\title{
Algae: A potential source for nanoparticle synthesis
}

\author{
Surindra Negi* \\ Department of Environmental Science, G.B. Pant University of Agriculture and \\ Technology, Pantnagar, U.S. Nagar- 263145 (Uttarakhand), India \\ Vir Singh \\ Department of Environmental Science, G.B. Pant University of Agriculture and \\ Technology, Pantnagar ,U.S. Nagar- 263145 (Uttarakhand), India \\ ${ }^{*}$ Corresponding author. E-mail: surindranegi05@gmail.com \\ more popularity, as the process is less toxic, cost effective and eco-friendly. Various bio- \\ logical sources such as algae, plants, bacteria, fungi etc. have been explored for their \\ potential to synthesize nanoparticles. In the literature, algae was found to be more relia- \\ ble source for the green synthesis of metal nanoparticles as they are readily available in \\ nature and are easy to grow in normal conditions. Metal nanoparticles like gold, silver and \\ iron synthesized from algal source have widespread application in treating environmental \\ pollutants like heavy metal removal, degradation of organic dyes, antimicrobial \\ agents etc.
}

\section{Article Info}

DOI:10.31018/jans.v10i4.1878 Received: August 22, 2018

Revised: September 16, 2018

Accepted: October 12, 2018

How to Cite

Negi, S. and Singh, V. (2018). Algae: A potential source for nanoparticle synthesis. Journal of Applied and Natural Science, 10(4): $1134-1140$

Keywords: Algae, Bioreduction, Metal nanoparticles, Nanotechnology, Reducing agent

\section{INTRODUCTION}

The prefix "nano" in the term nanotechnology is derived from a Greek word nanos, which means "dwarf". It relates, to any engineered matter that is one billionth $\left(10^{-9} \mathrm{~m}\right)$ in size or at least one of its dimensions, and is considered nanometer $(\mathrm{nm})$ (Hulkoti and Taranath 2014). Nanoparticles exhibit unique properties like chemical, physical, electronic, optical, thermal, mechanical, and biological properties that significantly differ from their bulk scale counterparts due to its small size, shape and size distribution (Kubik and Sugisaka, 2002; Goodsell et al., 2004; Fawcett et al., 2017). Nanoparticles are broadly divided into two groups of organic and inorganic nanoparticles. Organic nanoparticles include carbon nanoparticles (fullerenes) while some of the inorganic nanoparticles include magnetic nanoparticles, noble metal nanoparticles (gold and silver) and semiconductor nanoparticles (e.g. titanium dioxide and zinc oxide etc.). Nanoparticles exhibit distinctive visible properties because they are small enough to confine their electrons and produce quantum effects (Yadav et al., 2017). Metallic nanoparticles have possible applications in diverse areas such as electronics, cosmetics, coatings, packaging, and biotechnology. It has the ability to get attached to single strands of DNA without causing any destruction in chain (Thakkar et al., 2010).
Nanoparticles can be synthesized by physical and chemical methods which involve the use of hazardous chemicals and harmful radiation that can be life-threatening to human and environment. Apart from physical and chemical methods, biological methods are being explored nowadays for the synthesis of nanoparticles. Green chemistry is the cost-effective, non-toxic and environment friendly approach which involves the use of plant extracts and microorganisms (Abdelghany et al., 2017; Bansal et al., 2015), where biological components are used as a reducing and stabilizing agents, essential for the synthesis of nanoparticles. Nanoparticle synthesis can be accomplished using two approaches, viz. top-down approach and bottom-up approach. The top-down approach is a physical process where the size of the bulk material is reduced using various mechanical techniques to obtain nanoparticles of desired shape and size whereas bottom-up approach is the chemical process where the atoms and molecules are assembled into a larger structure with controlled deposition or reaction parameters (Saif et al., 2016; Rotello, 2004; Gottimukkala, 2017). Bottom-up approach is advantageous over topdown approaches as there is greater possibility of obtaining metal nanoparticles with relatively lesser defects and more homogeneous chemical compositions whereas top-down approach causes the imperfection in the surface structure and alters the 
Negi, S. and Singh, V. / J. Appl. \& Nat. Sci. 10 (4): 1134 -1140 (2018)

physical properties and surface chemistry due to the high aspect ratio (Thakkar et al., 2010).

Furthermore, diverse group of microorganisms such as algae (Aboelfetoh et al., 2017), bacteria (Shahverdi et al., 2007), fungi (Maliszewska et al., 2014) and plant leaf (Ahmed et al., 2016) are being used for the green synthesis of nanoparticles. The functional groups containing biological components such as alkaloids, terpenoids, phenolic compounds, polyphenols and proteins act as a reducing and capping agents during the synthesis of nanoparticles. The nanoparticles formed are thus prevented from the further chemical reaction and aggregation which increase their stability (Aboelfetoh et al., 2017; Makarov et al., 2014). The main aim of the study is to review the contribution of the researchers in the algae mediated green synthesis of silver, gold and iron metal nanoparticles and their application in day to day environment.

Microalgae facilitated biosynthesis of metal nanoparticles: Phyconanotechnology has been considered as a newer branch of nanoscience which involves the synthesis of nanoparticles using algal extract as they are relatively easy to handle, able to grow at a low temperature and are less toxic in nature (Sharma et al., 2016). Algae are the diverse group of unicellular and multicellular autotrophic organism that carries out the process of photosynthesis in the presence of sunlight. Depending on their size microscopic algae are known as microalgae whereas algae that are macroscopic in nature termed as macro algae. They are widely present in both marine and freshwater ecosystems as well as in terrestrial ecosystems in moist conditions. It helps in absorbing moisture from the atmosphere when in the symbiotic relationship with the lichen on rocks in dry and arid region. Algae is broadly classified into three main divisions viz. chlorophyta (green algae), phaeophyta (brown algae) and rhodophyta (red algae) all of which having chlorophyll $a$ in common. In addition to cellulose, the cell wall of chlorophyta, phaeophyta and rhodophyta contains xylans and mannans, alginic acid and fucoidan, xylan and galactans respectively (Davis et al. 2003). The rigid cell walls matrices contains several functional groups such as carbonyl, hydroxyl, carboxyl, sulfonate, thiol, amino and amidic groups (Subramaniyam et al. 2015; Kuyucak and Volesky, 1989) which play significant role in bulk metal reduction into its elemental form and its accumulation. In the researches, few varieties of both macro and microalgal species have been explored for the green synthesis of metal nanoparticles like gold (Ashokkumar et al., 2016), silver (Prasad et al., 2013), palladium (Momeni and Nabipour, 2015) and iron nanoparticles (Subramaniyam et al., 2015). Nanoparticles can be synthesized by extracellular and intracellular mechanism from algal biomass. In extracellular mechanism the bioreduction of metal ion to its nanoparticle takes place on the surface of the algal cell whereas in intracellular mechanism the enzymatic bioreduction process takes place inside the cell wall and cell membrane (Senapati et al., 2012).

Phycosynthesis of metallic nanoparticles:

Gold nanoparticles (AuNPs): Brown algae Turbinaria conoides and Sargassum tenerrimum were explored for their potential of producing gold nanoparticles. It was concluded that the presence of hydroxyl group in the algal extract facilitated the reduction of $\mathrm{Au}(\mathrm{III})$ to elemental gold and act as a capping agent for the synthesized spherical shaped gold nanoparticle of size 5- $57 \mathrm{~nm}$ (Ramakrishna, 2016). Another species of brown algae, Cystoseira baccata were found efficient in producing spherical shaped gold nanoparticle of size $8.4 \pm 2.2 \mathrm{~nm}$, polycrystalline in nature. The stability of nanoparticle was confirmed by zeta potential measurement $(-30.7 \pm 2.0 \mathrm{mV})$. It was suggested that the polysaccharides and polyphenols contains hydroxyl as a functional groups that helps in the bioreduction of bulk material into its elemental form and presence of protein acts as a capping agent and prevent agglomeration of gold nanoparticles (González-Ballesterosa et al., 2017). Green algae Pithophora Oedogonia synthesized spherical shaped gold nanoparticles of 33nm (Li and Zhang, 2016). El-Kassas and Elsheekh (2014), observed the change in the colour of solution from brown to red when aqueous extract of red Seaweed Corallina officinalis blended with the gold salt solution that confirmed the formation of gold nanoparticle. The synthesized nanoparticles were of size $14.6 \pm 1 \mathrm{~nm}$ of spherical shape. It was also concluded that hydroxyl and the carbonyl group assisted in the reduction and stabilization of nanoparticles. The nitrate reductase activity was found responsible for the bioreduction of gold ion to elemental gold (Oza et al., 2012). Ghodake and Lee (2011), reported the concentration dependent extracellular synthesis of gold nanoparticle within $20 \mathrm{~min}$ at $37^{\circ} \mathrm{C}$ using different fraction of aqueous extract of brown algae Laminaria japonica through a serial dilutions with distilled water i.e. 1:2.5, 1:5, 1:10, and 1:20 denoted as F1, F2, F3, F4 with2mM of chloroauric solution. All of the four fractions showed change in the colour from light yellow to dark red also the completion of the reaction was depended on the concentration of the aqueous extract. The change in the colour of the solution was due to surface Plasmon effect. F1 fraction was used for characterizing the resulted gold nanoparticles. The synthesized nanoparticles were spherical and the size ranged from $15-20 \mathrm{~nm}$. The crystalline nature of nanoparticle was confirmed using X-Ray diffraction technique. 
Negi, S. and Singh, V. / J. Appl. \& Nat. Sci. 10 (4): 1134 -1140 (2018)

Table 1. Algal species and their potential application in metal nanoparticle synthesis.

\begin{tabular}{|c|c|c|c|c|}
\hline Algal species & $\begin{array}{c}\text { Type of } \\
\text { nanoparticle }\end{array}$ & $\begin{array}{l}\text { Size of nano- } \\
\text { particles }\end{array}$ & Applications & References \\
\hline Caulerpa racemosa & $\mathrm{Ag}$ & $\sim 25 \mathrm{~nm}$ & $\begin{array}{l}\text { Catalytic degradation } \\
\text { of methylene Blue }\end{array}$ & Edison et al., 2016 \\
\hline Chlorella vulgaris & $\mathrm{Pd}$ & 2 to $15 \mathrm{~nm}$ & Catalytic activity & Eroglu et al., 2013 \\
\hline Codium capitatum & $\mathrm{Ag}$ & $30 \mathrm{~nm}$ & - & Kannan et al., 2013 \\
\hline Hypnea musciformis & $\mathrm{Ag}$ & 16 to $42 \mathrm{~nm}$ & Antibacterial activity & $\begin{array}{l}\text { Vadlapudi and } \\
\text { Amanchy et al., } 2017\end{array}$ \\
\hline Laurencia papillosa & $\mathrm{Au}$ & $3.5-53 \mathrm{~nm}$ & - & Montasser et al., 2017 \\
\hline Padina gymnospora & $\mathrm{Ag}$ & $25-40 \mathrm{~nm}$ & Antibacterial activitiy & Shiny et al., 2013 \\
\hline Padina pavonica (Linn.) & $\mathrm{Ag}$ & 10 to $72 \mathrm{~nm}$ & Microbicidal activity & Sahayaraj et al., 2012 \\
\hline Rhizoclonium fontinale & $\mathrm{Au}$ & $\sim 16 \mathrm{~nm}$ & - & Parial and Pal, 2015 \\
\hline Sargassum bovinum & $\mathrm{Pd}$ & 5 to $10 \mathrm{~nm}$ & $\begin{array}{l}\text { Electrochemical re- } \\
\text { duction of hydrogen } \\
\text { peroxide }\end{array}$ & $\begin{array}{l}\text { Momeni and Nabipour, } \\
2015\end{array}$ \\
\hline Sargassum muticum & $\mathrm{Ag}$ & $42.30-98.56 \mathrm{~nm}$ & Insecticidal activity & Moorthi et al., 2015 \\
\hline Sargassum wightii & $\mathrm{Pd}$ & 5- $37 \mathrm{~nm}$. & - $\quad 20$ & Prasad et al., 2015 \\
\hline Spirulina platensis & $\mathrm{Ag}$ & $\sim 5 \mathrm{~nm}$ & Antibacterial activity & Suganya et al., 2015 \\
\hline $\begin{array}{l}\text { Turbinaria conoides } \\
\text { Sargassum tenerrimum. }\end{array}$ & $\mathrm{Au}$ & $27-35 \mathrm{~nm}$. & $\begin{array}{l}\text { Catalytic reduction of } \\
\text { nitro compounds }\end{array}$ & $\begin{array}{l}\text { Ramakrishna et al., } \\
2016\end{array}$ \\
\hline Turbinaria conoides & $\begin{array}{l}\mathrm{Ag} \\
\mathrm{Au}\end{array}$ & $\begin{array}{l}2-17 \mathrm{~nm} \\
2-19 \mathrm{~nm}\end{array}$ & $\begin{array}{l}\text { Antimicrofouling Ac- } \\
\text { tivity }\end{array}$ & Vijayan et al., 2014 \\
\hline
\end{tabular}

Further, it was proposed that the electrostatic interaction between the salt solution and functional group chiefly polysaccharides involved in the bioreduction of $\mathrm{Au}$ (III) to elemental Au. Fluorescence spectra of Au NPs synthesized by $S$. marginatum biomasses were found to be centered at $550 \mathrm{~nm}$. Therefore, gold nanoparticles exhibit high efficient single photon-induced luminescence, which may be due to their ability to sustain resonating surface Plasmon with minimal damping (Rajathi et al., 2012). Micro algae Chlorella vulgaris also studied for the intracellular synthesis of spherical and polyhedral sized gold nanoparticles of size ranged from 40-60 nm (Luangpipat et al., 2011).

In an experiment it was found that Euglena gracilis shows maximum growth in mixotrophic condition. Increase in the number of living cells of algae under mixotrophic condition was then found responsible for the quicker formation of more stable gold nanoparticle as compared to the algal species grown under autotrophic condition (Dahoumane et al., 2016). Acidic and alkaline condition of the solution also influences the stability of synthesized nanoparticle. Gold nanoparticles were found stable within the $\mathrm{pH}$ range 5-9 whereas agglomeration of nanoparticles were observed at $\mathrm{pH} 3$ due to decrease in the surface charge of the particles and shows no change in the position of the absorbance at 550nm (Namvar et al., 2014).

Silver nanoparticles (AgNPs): Silver nanoparticles, due to its unique optical, electronic and catalytic properties have various applications in medical, industrial and commercial sectors. They are widely used as anti-inflammatory, anti-viral, antibacterial and antifungal agents also being used as nano-silver coated surgical instruments and im- plants and several other purposes (Azizi et al., 2013).

Pithophora oedogoni had successfully been explored for the synthesis of silver nanoparticle by showing maximum absorbance at $445 \mathrm{~nm}$. The aqueous algal extract was utilized to reduce silver nitrate solution into silver nanoparticles within few minutes. DLS (dynamic light scattering) and SEM instrumentation were used to confirm the size of the synthesized nanoparticles. The resulting silver nanoparticle size observed was $34.03 \mathrm{~nm}$ (Sinha et al., 2015). Aboelfetoh et al. (2017), used green marine algae, Caulerpa serrulata extract to reduce silver ion to spherical silver nanoparticles of $10 \pm 2$ $\mathrm{nm}$. Selvam and Shivkumar (2015), reported the biosynthesis of cubic shaped silver nanoparticles from the aqueous extract of red alga Hypnea musciformis of size 2- 55.8nm and also stated that the reduction of silver nanoparticles may be due to the presence of peptides.

Similarly, polydispersed type silver nanoparticles were synthesized from Chlorococcalean alga Chlorella vulgaris with mean size $12.62 \mathrm{~nm}$ and concluded that the presence of functional groups such as carboxylic and aromatic groups acts as a reducing agent and reduces silver ion to silver nanoparticles (Satapathy et al., 2015). The aqueous extract of microalga Scenedesmus sp. (IMMTCC-25) was used first time for the extracellular as well as intracellular synthesis of silver nanoparticles of size ranged from $5-10 \mathrm{~nm}$ and 15 to $20 \mathrm{~nm}$ respectively. In the experiment, the living cell as well as algal extract was treated separately with $5 \mathrm{mM}$ silver nitrate solution. In extracellular synthesis of silver nanoparticle the raw and the boiled extract of algal biomass was treated with the silver nitrate solution whereas in intracellular synthesis the live 
cell of algal biomass was extracted from their log phase and treated with silver nitrate solution and the culture were incubated for $72 \mathrm{hrs}$ at $28^{\circ} \mathrm{C}$. Formation of silver nanoparticles was observed by change in the colour of the solution from colourless transparent to reddish-yellow colour. It had been suggested that shape, size and conformation of protein molecules present as biological components is responsible for the stabilization of synthesized nanoparticles. The amount of reducing and capping agent in the algal extract was believed to form more stable nanoparticles. Therefore, boiled extract of algal biomass was found more effective in the formation of stable silver nanoparticle as compared to raw algal extract wherein the synthesized nanoparticles resulted in the agglomeration of the particles due to the low concentration of reducing agents (Jena et al., 2012).

Besides, the concentration of reducing and capping agent temperature also plays an important role in controlling the shape and size of the synthesized nanoparticles. Brown algae Cystophora moniliformis was found able to synthesized silver nanoparticle of size $75 \mathrm{~nm}$ at temperature less than $65^{\circ} \mathrm{C}$ whereas agglomeration of silver nanoparticle resulted due to increases in the size of the nanoparticles with increase in temperature up to $95^{\circ} \mathrm{C}$ (Prasad et al., 2013). The phytochemical analysis of green alga Pithophora oedogonia confirmed the presence of biomolecules namely carbohydrate, steroid, saponins, terpenoids, tannins and proteins which were found responsible for the reduction of $\mathrm{Ag}^{+}$ions into its elemental form and prevent agglomeration of synthesized silver nanoparticles (Sinha et al., 2015). Similarly, marine algae Caulerpa racemosa was successfully explored for the extracellular synthesis of silver nanoparticle of size ranged $5-25 \mathrm{~nm}$ (Kathiraven et al., 2015).

Iron nanoparticles (FeNPs): Limited researches have been reported in the formation of iron metal nanoparticle from algal species. Subramaniyam et al. (2015), explored the possibility of formation of iron nanoparticles for the very first time from soil microalga, Chlorococcum sp. MM1, the resulting spherical shaped iron nanoparticles were 20-50 $\mathrm{nm}$ in size. The presence of functional group attached with polysaccharides and glycoprotein was confirmed by FTIR analysis and believed to acts as a reducing and capping agent in the process of bioreduction. The aqueous extract of Microalga, Chlorococcum sp. was allowed to react with $0.1 \mathrm{M}$ iron chloride solution for $48 \mathrm{hr}$. Carbonyl and amine bonds from polysaccharides and glycoproteins present in the algal cell wall and was responsible for the bioreduction as well as capping of iron nanoparticle.

Application of metal nanoparticles in remediation of environmental pollutants: Metal nano- particles, such as platinum, silver, and gold are extensively used in products that directly come in contact with the human body, such as shampoos, detergent, soaps, shoes, cosmetic products, and toothpaste, besides medical and pharmaceutical applications (Singh et al., 2013). Silver nanoparticles of size 5-25 nm synthesized using marine algae Caulerpa racemosa also been tested for its antimicrobial activity against human pathogen such as $P$. mirabilis and $S$. aureus. It was concluded from the study that silver nanoparticles not only attack the cell membrane but also enter the bacterial cell and affects the respiratory chain cell division which ultimately leads to cell death (Kathiraven et al., 2015). Silver nanoparticles of size $34.03 \mathrm{~nm}$ synthesized from aqueous extract of green alga Pithophora oedogonia showed maximum zone of inhibition against Pseudomonas aeruginosa (MTCC 2581) (17.2 $\mathrm{mm}$ ) followed by Escherichia coli (MTCC 443) (16.8 mm). The antibacterial activity of gold nanoparticles was tested against gram negative and gram positive bacteria (Pseudomonas aeruginosa, Klebsiella oxytoca, Enterobacter faecalis, Klebsiella pneumoniae, Vibrio parahaemolyticus, Vibrio cholerae, Escherichia coli, Salmonella typhii, Salmonella paratyphi, and Proteus vulgaris). Maximum zone of inhibition was observed against $E$. faecalis (11 $\mathrm{mm}$ ) and minimum zone of inhibition was observed against $K$. pneumoniae $(6 \mathrm{~mm})$. E. coli $(0$ $\mathrm{mm}$ ) showed no zone of inhibition. Nanoparticles synthesized by green route are found to be highly effective against gram negative bacteria as compared to gram positive bacteria (Rajathi et al., 2012). Gram negative organisms possess a thin cell wall with peptidoglycans whereas gram positive organisms generally have thick cell wall made of peptidoglycans. Thus, an easier permeability could be achieved in the case of Gram negative organisms (Naveena and Prakash, 2013; Subramaniam and Suja, 2012).

Silver nanoparticle synthesized using micro algae, C. calcitrans, C. salina, I. galbana and T. gracilis showed zone of inhibition against human pathogens Klebsiella spp., Proteus vulgaris, Pseudomonas aeruginosa and against $E$. coli and act as a strong antibacterial agent (Merin et al., 2010). Subramaniyam et al. (2014), used Chlorococcum sp. MM11 to synthesize iron nanoparticles of size 20-50 nm and tested its absorption efficiency. The study showed that the synthesized nanoparticles removed $92 \%$ of $4 \mathrm{mg} \mathrm{L}^{-1}$ hexavalent chromium to $\mathrm{Cr}$ (III) whereas bulk iron only reduced $25 \%$ concluding that iron nanoparticle is much more efficient in removing contamination from environment. Silver nanoparticle synthesized from green algal species Caulerpa serrulata also found effective in catalysis of Congo red (CR) dye as it provides large surface area for exchange of electron between electron donor and acceptor (Aboelfetoh 
et al., 2017). Besides antibacterial property against gram positive and gram negative bacteria, Silver nanoparticles synthesized from freshwater microalgae Chlorella pyrenoidosa has also been tested for its photocatalytic activity against methylene blue dye and further suggested its application in the treatment of effluent containing hazardous dye as a result of chemical processes in the industrial sectors (Aziz et al., 2015). Some of the important work in the field of phyconanotechnology has been shown in Table 1.

\section{Conclusion}

The eco- friendly and cost effective biological synthesis of metallic nanoparticles is a promising alternative to the conventional physical and chemical method. Several researchers have explored the biological potential of algae to synthesize nanoparticles of various shapes and sizes under different conditions. It was observed that the biomolecules of algae act as a reducing and capping agent without using any toxic compounds and successfully produced stabilized nanoparticles. Excessive use of toxic organic and inorganic pollutants, degrading the overall quality of environment with time, hence development of eco-friendly techniques is the need of the hour to minimize the adverse effects of pollutants. Phyconanotechnology, is the best technique to remediate the pollutants presents in air, water and soil without having any harmful impact on environment. Despite successful bioreduction of metal salt to its elemental state and its application in various fields, the mechanism involved during synthesis is not known at the molecular level. Also, several other species of algal biomass is still unexplored. Therefore, further researches must be carried out to identify the most suitable and efficient biological source for nanoparticle synthesis of smaller diameter with detailed mechanism involved.

\section{REFERENCES}

1. Abdelghany, T. M., Al-Rajhi, A.M. H., Al Abboud, M. A., Alawlaqi, M. M., Magdah, A. G., Helmy, E. A. M., Mabrouk, A. S. (2017). Recent Advances in Green Synthesis of Silver Nanoparticles and Their Applications: About Future Directions. A Review. BioNanoSci. DOI 10.1007/s12668-017-0413-3.

2. Aboelfetoh, E. F., El-Shenody, R. A., Ghobara, M. M. (2017). Eco-friendly synthesis of silver nanoparticles using green algae (Caulerpaserrulata): reaction optimization, catalytic and antibacterial activities. Environmental Monitoring and Assessment, 189:349.

3. Ahmed, S., Saifullah, Ahmad, M., Swami, B. L. and Ikram S. (2016). Green synthesis of silver nanoparticles using Azadirachtaindica aqueous leaf extract.Journal of Radiation Research and Applied Sciences, 9: 1-7.

4. Ashok kumar, T. and Vijayaraghavan, K. (2016). Brown seaweed-mediated biosynthesis of gold nanoparticles. Journal of Environment and Biotechnology Research, 2(1): 45-50.
5. Aziz, N., Faraz, M., Pandey, R., Shakir, M., Fatma, T., Varma, A., Barman, I., and Prasad R. (2015). Facile Algae-Derived Route to Biogenic Silver Nanoparticles: Synthesis, Antibacterial and Photocatalytic Properties NAFE. Langmuir, 31(42): 11605-11612.

6. Azizi, S., Namvar, F., Mahdavi, M., Ahmad, M. B. and Mohamad, R. (2013).Biosynthesis of silver nanoparticles using brown marine Macroalga, SargassumMuticum aqueous extract. Materials, 6: 5942-5950.

7. Bansal, M., Bansal, A., Sharma, M., and Kanwar, P. (2015).Green synthesis of gold and silver nanoparticles.Research Journal of Pharmaceutical, Biological and Chemical Sciences, 6(3): 1710-1716.

8. Dahoumane, S.A., Yéprémian, C., Djédiat, C., Couté, A., Fiévet, F., Coradin, T., and Brayner, R. (2016). Improvement of kinetics, yield, and colloidal stability of biogenic gold nanoparticles using living cells of Euglena gracilis microalga.Journal of Nanoparticle Research, Springer Verlag, 18 (3): 79.

9. Davis, T. A., Voleskya, B. and Muccib, A. (2003).A review of the biochemistry of heavy metal biosorption by brown algae. Water Research 37: 4311-4330.

10.Edison, T. N.J. I., Atchudan, R., Kamal, C. and Lee, Y. R. (2016).Caulerparacemosa: a marine green alga for eco-friendly synthesis of silver nanoparticles and its catalytic degradation of methyleneblue. Bioprocess Biosyst. Eng, 39:1401-1408

11.El-Kassas H.Y., El-Sheekh, M. M. (2014).Cytotoxic activity of biosynthesized gold nanoparticles with an extract of the red seaweed Corallina officinalis on the MCF-7 human breast cancer cell line. Asian Pacific Journal of Cancer Prevention, 15(10): 4311-7.

12.Eroglu, E., Chen, X., Bradshaw, M. et al. (2013). Biogenic production of palladium nanocrystals using microalgae and their immobilization on chitosan nanofibers for catalytic applications. RSC Advances, 3: 1009-1012.

13.Fawcett, D., Jennifer, J. V., Shah, M., Sharma, S. B., Gérrard, E. J. P. (2017). A review of current research into the biogenic synthesis of metal and metal oxide nanoparticles via marine algae and seagrasses. Journal of Nanoscience, 15 Article ID 8013850.

14.Ghodake, G. and Lee, D. S. (2011). Biological Synthesis of Gold Nanoparticles Using the Aqueous Extract of the Brown Algae Laminaria Japonica. Journal of Nanoelectronics and Optoelectronics 6, (3) 268271.

15.González-Ballesteros, N., Prado-López, S., Rodríguez-González, J.B., Lastra, M., RodríguezArgüelles, M.C (2017). Green synthesis of gold nanoparticles using brown algae Cystoseira baccata: Its activity in colon cancer cells. Colloids and Surfaces B: Biointerfaces, 153: 190-198.

16.González-Ballesterosa, N., Prado-Lópezb, S., Rodríguez-Gonzálezc, J.B., Lastrad, M. and Rodríguez-Argüellesa, M.C. (2017). Green synthesis of gold nanoparticles using brown algae Cystoseirabaccata: Its activity in colon cancer. Colloids and Surfaces B: Biointerfaces, 153: 190-198.

17.Goodsell, D. S. (2004). Bionanotechnology: Lessons from Nature, John Wiley \& Sons, Hoboken, NJ, USA.

18.Gottimukkala, K.S.V. (2017). Green synthesis of iron nanoparticles using green tea leaves extract. Journal of Nanomedicine \& Biotherapeutic Discovery, 7:1.

19.Hulkoti, N.I. and Taranath, T.C. (2014).Biosynthesis of nanoparticles using microbes-a review. Colloids and Surfaces B: Biointerfaces, 121: 474-483. 
Negi, S. and Singh, V. / J. Appl. \& Nat. Sci. 10 (4): 1134 -1140 (2018)

20.Jena, J., Pradhan, N., Dash, B.P., Sukla, L.B. and Panda, P.K. (2012).Biosynthesis and characterization of silver nanoparticles using microalgae Chlorococcum humicolaand its antibacterial activity. International Journal of Nanomaterials and Biostructures, 3(1):1-8

21.Kannan, R.R.R., Stirk, W.A. and Staden,J. V. (2013). Synthesis of silver nanoparticles using the seaweed Codium capitatum P.C. Silva (Chlorophyceae). South African Journal of Botany, 86: 1-4.

22.Kathiraven, T., Sundaramanickam, A., Shanmugam, N. and Balasubramanian, T. (2015). Green synthesis of silver nanoparticles using marine algae Caulerpa racemosa and their antibacterial activity against some human pathogens. Applied Nanoscience, 5: 499-504.

23.Kubik, K. B. and Sugisaka, M. (2002). From molecular biology to nanotechnology and nanomedicine, BioSystems, 65, no. 2-3, 123-138.

24.Kuyucak, N., Volesky, B. (1989). Accumulation of gold by algal biosorbent. Biogeosciences, 1:189204.

25.Li, L. and Zhang, Z. (2016). Biosynthesis of gold nanoparticles using green alga Pithophoraoedogonia with their electrochemical performance for determining carbendazim in soil. International Journal of Electrochemical Science, 11: 4550 - 4559.

26.Luangpipat, T., Beattie, I. R., Chisti, Y. and Haverkamp, R. G. (2011). Gold nanoparticles produced in a microalga. Journal of Nanoparticle Research, 13: 6439-6445.

27.Makarov, V. V., Love, A. J., Sinitsyna, O. V., Makarova, S. S., Yaminsky, I. V., Taliansky, M. E., \&Kalinina, N. O. (2014). "Green" Nanotechnologies: Synthesis of Metal Nanoparticles Using Plants. ActaNaturae, 6(1): 35-44.

28.Maliszewska, I., Juraszek, A. and Bielska, K. (2014).Green Synthesis and Characterization of Silver Nanoparticles Using Ascomycota Fungi Penicilliumn algiovense AJ12. Journal of Clusture Science, 25: 989-1004.

29.Merin, D. D., Prakash, S. and Bhimba, B.V. (2010). Antibacterial screening of silver nanoparticles synthesized by marine micro algae. Asian Pacific Journal of Tropical Medicine, 797-799.

30.Momeni, S. and Nabipour, I. (2015). A simple green synthesis of palladium nanoparticles with Sargassum algae and their electrocatalytic activities towards hydrogen peroxide. Applied Biochemistry and Biotechnology, 176(7): 1937-49.

31.Montasser, M. S., Hegazi, M.M., Younes, A. M., Dashti, N. H., El-Sharkawey, A. E. (2017). Effect of Gold Chloride Concentration and Volume on Size and Shape of Biological Synthesized Gold Nanoparticles (AuNPs) Using Red Algae (Laurenciapapillosa). Science of Advanced Materials, 9 (7): 1105-1113(9).

32.Moorthi, P.V., Balasubramanian, C. and Mohan, S. (2015). Appllied Biochemistry and Biotechnology, 175: 135

33.Namvar, F., Azizi, S., Ahmad, M. B., Shameli, K., Mohamad, R., Mahdavi, M. and Tahir, P. M. (2014).Green synthesis and characterization of gold nanoparticles using the marine macroalgae Sargassum muticum. Research on Chemical Intermediates, 41 (8): 5723-5730.

34.Naveena, B. E., and Prakash, S. (2013). Biological synthesis of gold nanoparticles using marine algae
Gracilaria corticata and its application as a potent antimicrobial and antioxidant agent. Asian Journal of Pharmaceutical and Clinical Research, 6(2): 179-182.

35.Oza, G., Pandey, S., Mewada, A., Kalita, G. and Sharon, M. (2012).Facile biosynthesis of gold nanoparticles exploiting optimum $\mathrm{pH}$ and temperature of freshwater alga Chlorella pyrenoidusa. Advances in Applied Science Research, 3(3): 1405-1412.

36.Parial, D. and Pal, R. (2015). Biosynthesis of monodisperse gold nanoparticles by green alga Rhizoclonium and associated biochemical changes. Journal of Applied Phycology 27: 975.

37.Prasad, B. S. N., Padmesh, T.V.N., Kumar, V. G. and Govindaraju, K. (2015). Seaweed (SargassumwightiiGreville) assisted green synthesis of palladium nanoparticles. Research J. Pharm. and Tech, . 8(4).

38.Prasad, T. N. V. K. V., Kambala, V.S. R. and Naidu, R. (2013). Phyconanotechnology: synthesis of silver nanoparticles using brown marine algae Cystophora moniliformis and their characterisation. Journal of Applied Phycology, 25:177-182.

39.Rajathi, F. A. A., Parthiban, C., Kumar, V. G., Anantharaman, P. (2012). Biosynthesis of antibacterial gold nanoparticles using brown alga, Stoechospermum marginatum (kützing). Spectrochimica Acta Part A: Molecular and Biomolecular Spectroscopy, 99: 166-173.

40.Ramakrishna, M., Babu, D. R., Gengan, R. M. and Rao, S. C. G. N. (2016). Phytoremediation using Wetland Plants: An ecosustainable approach. International Journal of Phytoremediation, 10 (2): 133-160.

41.Ramakrishna, M., Babu, D. R., Gengan, R. M., Chandra, S. and Rao, G. N. (2016). Green synthesis of gold nanoparticles using marine algae and evaluation of their catalytic activity. J. Nanostruct. Chem., 6:1-13.

42.Rotello, V.M. (2004). Nanoparticles: Building Blocks for Nanotechnology. Springer Science \& Business Media: New York, NY, USA.

43.Sahayaraj, K., Rajesh, S. and Rathi, J.M. (2012). Silver nanoparticles biosynthesis using marine alga Padinapavonica(Linn.) and its microbicidalactivity. Digest Journal of Nanomaterials and Biostructures, 7 (4): 1557-1567.

44.Saif, S., Tahir, A. and Chen., Y. (2016). Green synthesis of iron nanoparticles and their environmental applications and implications. Nanomaterials, 6, 209.

45.Satapathy, S., Shukla, S.P., Sandeep, K. P., Singh, A. R., Sharma, N. (2015). Evaluation of the performance of an algal bioreactor for silver nanoparticle production. Journal of Applied Phycology, 27 (1): 285 $-291$.

46.Selvam, G. G. and Sivakumar, K. (2015). Phycosynthesis of silver nanoparticles and photocatalytic degradation of methyl orange dye using silver $(\mathrm{Ag})$ nanoparticles synthesized from Hypnea musciformis (Wulfen) J.V. Lamouroux. Applied Nanoscience, 5 (5): 617-622.

47.Senapati, S., Syed, A., Moeez, S., Kumar, A. and Absar, A. (2012). Intracellular synthesis of gold nanoparticles using alga Tetraselmiskochinensis.Materials Letters, 79: 116-11.

48.Shahverdi, A. R., Minaeian, S., Shahverdi, H. R., Jamalifar, H., Nohi, A. A. (2007). Rapid synthesis of silver nanoparticles using culture supernatants of Enterobacteria: A novel biological approach. Pro- 
cess Biochemistry, 42 (5): 919-923.

49.Sharma, A., Sharma, S., Sharma K., Chetri, S. P. K., Vashishtha, A., Singh, P., Kumar, R., Rathi, B., Agrawal V. (2016). Algae as crucial organisms in advancing nanotechnology: a systematic review. Journal of Appllied Phycology, 28: 1759-1774.

50.Shiny, P. J., Mukherjee, A. and Chandrasekaran,N. (2013).Marine algae mediated synthesis of the silver nanoparticles and its antibacterial efficiency. International Journal of Pharmacy and Pharmaceutical Sciences, 5 (2): 239-241.

51.Singaravelu, G., Arockiamary, J. S., Kumar, V. G., Govindaraju, K. (2007). A novel extracellular synthesis of monodisperse gold nanoparticles using marine alga, Sargassum wightii Greville. Colloids and SurfacesB: Biointerfaces, 57: 97-101.

52.Singh, M., Kalaivani, Manikandan, S., Sangeetha, N. and Kumaraguru K. (2013). Facile green synthesis of variable metallic gold nanoparticle using Padina gymnospora, a brown marine macroalga. Applied Nanoscience 3: 145-151.

53.Sinha, S. N., Paul, D., Halder, N., Sengupta, D. and Patra, S. K. (2015). Green synthesis of silver nanoparticles using fresh water green alga Pithophora oedogonia (Mont.). Applied Nanoscience 5:703-709.

54.Subramaniam, V. and Suja S. (2012). Green synthesis of silver nanoparticles using Coleus amboinicus lour, antioxidant activity and invitro cytotoxixity against Ehrlich's Ascite carcinoma. Journal of Pharmacy Research, 5 (2): 1268- 1272.
55.Subramaniyam, V., Ramraj, S., Bose, S., Thavamani, P., Megharaj, M., Chen, Z. and Naidu, R. (2015). Chlorococcum sp. MM11- a novel Phyco-nanofactory for the synthesis of iron NP. Journal of Appllied Phycology, 27(5): 1861-1869.

56.Suganya, K. S. U., Govindaraju, K., Kumar, V. G, Dhas, T. S., Karthick, V., Singaravelu, G., and Elanchezhiyan, M. (2015). Blue green alga mediated synthesis of gold nanoparticles and its antibacterial efficacy against Gram positive organisms. Materials Science and Engineering C, 47: 351-356.

57. Thakkar, K. N., Mhatre, S. S. and Parikh, R.Y. (2010). Biological synthesis of metallic nanoparticles. Nanomedicine, 6(2): 257-62.

58.Vadlapudi, V. and Amanchy, R. (2017). Synthesis, Characterization and Antibacterial Activity of Silver Nanoparticles from Red Algae, Hypnea musciformis. Advances in Biological Research, 11 (5): 242-249.

59.Vijayan, S. R., Santhiyagu, P., Singamuthu, M., Ahila, N. K., Jayaraman, R. and Ethiraj, K. (2014). Synthesis and characterization of silver and gold nanoparticles using aqueous extract of seaweed, Turbinariaconoides, and their antimicrofouling activity. The Scientific World Journal Volume, Article ID 938272, 10 pages.

60.Yadav, K. K., Singh, J. K., Gupta, N. and Kumar, V. (2017). A review of nanobioremediation technologies for environmental cleanup: a novel biological approach. Journal of Materials and Environmental Sciences 8(2): 740-757. 